\title{
TUNAS
}

JURNAL PENDIDIKAN GURU PENDIDIKAN DASAR

http://journal.umpalangkaraya.ac.id/index.php/tunas

Volume 6 Nomor 1, Desember 2020 (46-51)

\section{MENINGKATKAN KOIMPETENSI GURU SDN 1 LANDASAN ULIN UTARA DALAMI PENGGUNAAN MEDIA TIK BERBASIS ANDROID MELALUI TUTOR SEBAYA}

\author{
Improving SDN 1 Landasan Ulin Utara Teachers Competency In The Use Of \\ Android Based ICT Media Through a Tutor \\ Suwardi \\ SDN I Landasan Ulin Utara, Banjarbaru, Kalimantan Selatan, Indonesia
}

\section{ARTIKEL INFO}

Diterima

September 2020

Dipublikasi

Desember 2020 *e-mail : suwardiberlina@yahoo.c o.id

\section{ABSTRAK}

Era Revolusi Industri 4.0 menuntut dunia pendidikan untuk meningkatkan budaya literasi data, teknologi, dan manusia bagi pengembangan segala jenis pekerjaan di era ini. Dalam Peraturan Menteri Pendidikan Nasional Nomor 16 Tahun 2007 tentang Standar Kualifikasi Akademik dan Kompetensi Guru terdapat 4 kompetensi yang harus dikuasai guru salah satunya adalah kompetensi pedagogik, seorang guru harus mampu menggunakan serta memanfaatkan teknologi informasi dan komunikasi (TIK) untuk kepentingan pembelajaran. Oleh karenanya, guru dituntut harus bisa menggunakan dan memanfaatkan TIK sebagai media dalam proses pembelajaran. Penulisan Best Practise ini bertujuan untuk Meningkatkan Kompetensi guru SDN I Landasan Ulin Utara dalam penggunaan media TIK berbasis android melalui tutor sebaya Tahun 2019. Subjek yang digunakan dalam best practise ini adalah guru di SDN I Landasan Ulin Utara yang berjumlah 3I orang, dari jumlah tersebut hanya 6 orang yang memanfaatkan media pembelajaran berbasis android dalam pembelajaran, setelah pelaksanaan evaluasi dilakukan dengan mengamati peningkatan kompetensi guru setelah mengajar menggunakan IT. Hasil yang dicapai, ada 20 guru yang mampu menggunakan android dalam pembelajaran.

Kata kunci: TIK, Media Pembelajaran Berbasis Android.

\section{ABSTRACT}

The Industrial Revolution 4.0 demands the education world to improve the culture of data, technology and human literacy for the development of all types of jobs in this era. The Minister of National Education Regulation Number 16 Year 2007 regarding Academic Qualification Standards and Teacher Competencies there are 4 competencies that must be mastered by teachers, one of which is pedagogical competence, a teacher must be able to use and utilize information and communication technology (ICT) for learning purposes. Therefore, teachers are required to be able to use and utilize ICT as a medium in the learning process. The writing of this Best Practice aims to Improve the Competency of SDN I Landasan Ulin Utara teachers in using Android-based ICT media through peer tutors in 2019. The subjects used in this best practice are the teachers at SDN I Landasan Ulin Utara, amounting to 31 people, from that number only 6 people who use the Android-based learning media in learning, after the evaluation is done by observing the improvement in teacher competence after teaching using IT. The results achieved, there are 20 teachers who are able to use Android in learning.

Keywords:Android-Based Learning, ICT. 


\section{Jurnal Pendidikan Guru Sekolah Dasar PENDAHULUAN}

Pesatnya teknologi dan informasi yang telah merambah ke semua sektor kehidupan masyarakat menuntut seorang guru memiliki kemampuan untuk menguasai teknologi tersebut. Menurut Kustandi \& Sutjipto (20II) bahwa media sebagai alat bantu mengajar, berkembang sedemikian pesatnya sesuai dengan kemajuan teknologi. ragam dan jenis media pun cukup banyak sehingga dapat dimanfaatkan sesuai dengan kondisi, waktu, keuangan maupun materi. Untuk mendapatkan hasil pembelajaran yang maksimal pemilihan media merupakan salah satu faktor penting, Untuk itu pemilihan media pembelajaran harus sesuai dengan pembelajaran tersebut.

Dunia pendidikan tidak lepas dari TIK. Bahkan awal mula perkembangan komputer dan internet dewasa ini adalah fakta dari risetriset yang dikerjakan oleh kalangan akademisi. Saat ini pendidikan juga membutuhkan TIK yang sama besarnya seperti kalangan dunia kerja. Dunia pendidikan erat kaitannya dengan informasi dan pengetahuan. Oleh karena itu, akses yang mudah kepada informasi dan pengetahuan menjadi sangat penting.

Pemanfaatan TIK dalam bidang pendidikan sangatlah banyak diantaranya; I) memudahkan mengakses informasi tentang dunia pendidikan dimanapun serta kapanpun, 2) materi-materi pelajaran disampaikan interaktif dan menarik, 3) berbagai kendala pembelajaran jarak jauh seperti kendala biaya dan waktu dapat dihindari dengan mengikuti kelas online.

Peraturan Menteri Pendidikan Nasional Nomor 16 Tahun 2007 tentang Standar Kualifikasi Akademik dan Kompetensi Guru terdapat 4 kompetensi yang harus dikuasai oleh guru diantaranya yaitu kompetensi pedagogik, kompetensi profesional, kompetensi individual dan kompetensi sosial. Di dalam kompetensi pedagogik disebutkan bahwa seorang guru harus mampu menggunakan serta memanfaatkan teknologi informasi dan komunikasi guna untuk kepentingan pembelajaran. Oleh karena itu, guru dituntut harus bisa menggunakan serta memanfaatkan teknologi informasi dan komunikasi sebagai media dalam proses pembelajaran sehari-hari.

Keadaan saat ini mengharapkan guru dapat meningkatkan kompetensi salah satunya dalam penguasaan Teknologi Informasi dan Komunikasi (TIK). Hal ini diperlukan untuk mendukung kegiatan pembelajaran yang menarik, efektif dan efisien. Oleh karenanya, perlu diadakan suatu kegiatan atau pelatihan untuk menambah pengetahuan/wawasan dan keterampilan guru tentang TIK. Pelatihan yang diberikan diharapkan dapat diaplikasikan guru dalam penggunaan media teknologi informasi untuk meningkatkan efektifitas dan efisiensi dalam kegiatan belajar mengajar.

Berdasarkan kondisi yang terjadi sekarang terdapat beberapa masalah yang akan diatasi pada kegiatan ini, antara lain pemanfaatan penggunaan smartphone oleh guru dan peserta didik masih sebatas pada alat komunikasi dan hiburan, padahal dapat dioptimalkan penggunaannya sebagai media pembelajaran berbasis android. Kemampuan yang dimiliki guru dalam memanfaatkan android sebagai media belajar juga belum merata. Guru dengan usia lebih tua cenderung kurang mengerti mengoperasikan android untuk mendukung pembelajaran agar lebih menarik dan efisien. Oleh karenanya diperlukan metode tutor sebaya untuk mengatasi kendala tersebut.

Tutor sebaya dilakukan dengan kegiatan diskusi. Istilah diskusi menurut Semi (2008:10) adalah suatu percakapan yang terarah yang berbentuk pertukaran pikiran antara dua orang atau lebih secara lisan untuk mendapatkan kesepakatan atau kecocokan dalam usaha memecahkan masalah yang dihadapi. Karena permaslahan yang dihadapi adalah dalam penguasaan TIK, maka diskusi difokuskan pada peningkatan penguasaan TIK. 
Jurnal Pendidikan Guru Sekolah Dasar

Tutor berarti orang yang membimbing atau member pelajaran kepada seseorang atau sejumlah siswa. Sedang sebaya dapat dikatakan mempunyai umur yang sama, atau mempunyai kedudukan atau peran yang sama. Tutor sebaya yang dimaksud pada penelitian tindakan ini adalah guru yang mempunyai kemampuan lebih di bidang TIK mengajar guru lainnya yang kurang menguasai TIK.

Salah satu upaya yang dilakukan oleh untuk mengembangkan kompetensi pedagogik dan profesional dibidang TIK adalah dengan mengikuti pelatihan penggunaan media TIK berbasis android melalui tutor sebaya.

\section{METODOLOGI PENELITIAN}

Penelitian ini merupakan penelitian tindakan dengan tujuan untuk mengetahui metode tutor sebaya dalam meningkatkan kemampuan guru di SDN I Landasan Ulin Utara. Pencapaian tujuan yang telah ditetapkan dalam kegiatan ini dilaksanakan dengan beberapa metode berikut: I. Metode Ceramah, 2. Metode Demonstras, 3. Metode Praktek/Latihan untuk mempraktekkan pembuatan media pembelajaran berbasis android yang sudah disampaikan melalui tutor sebaya.

Teknik pengumpulan data menggunakan angket mengenai persepsi peserta terhadap pelaksanaan pelatihan. Indikator keberhasilan pelatihan ini meliputi tingkat pembelajaran (mengukur tingkat pembelajaran yang dialami oleh peserta pelatihan), tingkat perilaku (mengukur implementasi hasil pelatihan), tingkat reaksi (mengukur tingkat kepuasan peserta pelatihan terhadap program tutor sebaya) dan tingkat hasil (mengukur keberhasilan tutor sebaya). Pembinaan guru SDN I Landasan Ulin Utara melalui metode turo sebaya dilakukan setelah anak-anak pulang sekolah sampai waktu/jam kerja habis (I4.00-15.00) 2 kali seminggu selama 4 bulan (Agustus-Desember 2019).

\section{HASIL DAN PEMBAHASAN}

Kegiatan pembelajaran TIK terfokus dengan bantuan tutor sebaya pada guru didapatkan hasil bahwa guru SDN I Landasan Ulin Utara yang terampil menggunakan android berjumlah 31 orang. Akan tetapi hanya sedikit yang memanfaatkan android dalam pembelajaran yakni berjumlah 6 orang. Kebanyakan guru hanya memanfaatkan android sebagai akses media komunikasi dalam media sosial. Padahal perkembangan TIK pun terus meningkat seiring dengan meningkatnya kebutuhan manusia.

Trend penggunaan e- yang berarti elektronik bermunculan. Seperti e-education, e-government, e-learning dan lain sebagainya. Dengan demikian, penguasaan (pemanfaatan) IT oleh guru dalam pembelajaran sangat penting. Tetapi tidak semua guru dapat menguasai dan memanfaatkannya. Oleh karena itu, kemajuan tersebut harus diikuti dengan pengembangan sumber daya tenaga pendidik. Untuk menunjang pengembangan tersebut, dibutuhkan juga fasilitas atau sarana yang berhubungan dengan teknologi, informasi, dan komunikasi.

Kegiatan pelatihan biasa dirasa kurang efektif, sehingga perlu dicari terobosan baru yang lebih efektif. Karena para guru mempunyai kebiasaan diskusi bersama seusai kegiatan pembelajaran, maka kegiatan pembelajaran bersama melalui diskusi kelompok dengan bahan bahasan terfokus dirasa efektif. Di samping itu, beberapa guru yang sudah menguasai TIK dapat dijadikan tutor sebaya. Sehingga langkah pemecahan masalah melalui kegiatan diskusi terfokus dengan bantuan tutor sebaya dipilih sebagai strategi pemecahan masalah penguasaan TIK pada guru SDN I Landasan Ulin Utara.

Dalam penggunaan media TIK berbasis android dengan menawarkan kesediaan guru yang terampil menggunakan android dalam pembelajaran untuk mendampingi guru yang hanya menggunakan android untuk media sosial. Proses pembinaan dilakukan setelah anak-anak pulang sekolah sampai waktu/jam 
Jurnal Pendidikan Guru Sekolah Dasar

kerja habis (14.00-15.00) 2 kali seminggu selama 4 bulan (Agustus-Desember 2019). Pemahaman guru dalam menggunakan IT akan menunjukkan meningkatnya kompetensi yang ada dalam dirinya. Kegiatan pendampingan ini dapat ditelusuri melalui https://youtu.be/t2Pc23ISReE

Pelaksanaan evaluasi dilakukan dengan mengamati peningkatan kompetensi guru setelah mengajar menggunakan IT. Hasil yang dicapai yakni ada 20 guru yang mampu menggunakan android dalam pembelajaran, sedangkan 5 orang guru masih belum mampu menggunakan android dalam pembelajaran. Penyebab guru tersebut belum terampil menggunakan android sebagai media pembelajaran yakni sebagai berikut.

I) Takut akan kesalahan yang diperbuat, sehingga dapat mengakibatkan kerusakan media.

2) Usia yang sudah tua dan mendekati pensiun.

3) Kurang memahami bahasa teknik TI (bahasa Inggris).

4) Kesadaran yang masih rendah mengenai arti penting teknologi untuk menunjang professi guru dalam menyelesaikan tugas.

5) Tidak adanya kesempatan dan peluang untuk bisa lebih dekat dengan teknologi.

Adapun motivasi dari guru-guru lain yang didapat setelah pelatihan dengan tutor sebaya mengalami peningkatan sehingga dapat menggunakan android sebagai bahan pembelajaran untuk siswa. Hal demikian didukung dalam beberapa faktor yakni sebagai berikut.

I) Kualitas pelatihan dengan metode tutor sebaya sangat bagus karena tidak ada kecanggungan dalam berkomunikasi sehingga dapat menambah pengetahuan dan wawasan guru. Hal ini sesuai dengan pendapat Suryo dan Amin (1982:5I) tentang kelebihan metode tutor sebaya yaitu adanya suasana hubungan yang lebih dekat dan akrab antara siswa yang dibantu dengan siswa sebagai tutor pembantu.

2) Tidak ingin ketinggalan informasi.

3) Gaya hidup

4) Ditunjang kondisi keuangan yang baik (dapat tunjangan profesi).

5) Keinginan yang kuat untuk mengubah proses pembelajaran menjadi lebih baik, guru sangat termotivasi untuk bisa, karena seiring dengan perkembangan zaman saat ini dan ingin lebih menguasai lagi tentang materi ini karena merupakan ilmu yang baru yang bisa digunakan untuk mengajar siswa dengan metode yang baru. Motivasi guru tinggi karena materi pelatihan bisa untuk bahan mengajar ke peserta didik.

Kitchenham (20I I) berpendapat bahwa pemanfaatan smartphone dalam program pendidikan menjadikan ini sebagai salah satu bentuk perangkat yang dapat digunakan sebagai alternatif dalam pengembangan media. Penggunaan smartphone dalam pendidikan dikenal sebagai teknologi mobile learning ( $\mathrm{m}$ Learning).

Pemanfaatan m-Learning dinyatakan oleh Gonzalez (2015) dapat memberikan kontribusi yang positif kepada peserta untuk mengakses bahan belajar ataupun sebagai media pembelajaran. Selain itu, Laurillard (2007) berpendapat bahwa dengan menggunakan smartphone dalam pendidikan, membuat teknologi memiliki peran yang sentral untuk dapat digunakan sebagai sarana penyampai informasi kepada siswa melalui teknologi perangkat mobile.

Menurut Rogozin (2012) menyatakan bahwa dengan menggunakan smartphone 
Jurnal Pendidikan Guru Sekolah Dasar

sebagai media pembelajaran memberikan kesempatan belajar yang lebih mendalam bagi siswa karena dengan menggunakan smartphone siswa dapat mengembangkan pembelajaran melalui penelusuran informasi dari internet, serta melatih keterampilan mereka dalam melaksanakan praktikum karena prinsip mobilitas yang dimiliki oleh smartphone. Lebih lanjut dikatakan bahwa dengan menggunakan smartphone siswa mampu membangun kompetensi mereka dengan cara yang dinamis.

\section{KESIMPULAN}

Berdasarkan hasil dan pembahasan masalah pada best practice ini, dapat disimpulkan bahwa penggunaan media TIK berbasis android melalui tutor sebaya yang dilaksanakan guru di SDN I Landasan Ulin Utara berjalan dengan baik. Dari 31 orang guru yang dapat menggunakan android. Setelah dilaksanaan evaluasi dilakukan dengan mengamati peningkatan kompetensi guru setelah mengajar menggunakan IT. Hasil yang dicapai, ada 20 guru yang mampu menggunakan android dalam pembelajaran.

\section{DAFTAR PUSTAKA}

Azhar, A. 20I I. Media Pemebalajaran. Jakarta: PT.Raja Grafindo Persada.

Kusnandi, C. \& Sutjipto, B. 20ll. Media Pembelajaran Manual dan Digital, Bogor: Galia Indonesia.

Djamarah, S. B. \& Zain, A. 2002. Strategi Belajar Mengajar. Jakarta: Rieneka Cipta.

Gonzalez, M.A., Martin, M.E.,Liamas, C., 2015. Teaching and learning physicswith smartphones. Journal of Cases on InformationTechnology, 17, 31-50.

Kitchenham, A. 20II. Models for interdisciplinary mobile learning: delivering information to students. Hersey PA: IGI Global.
Kustandi, C., \& Sutjipto, B. 20II. Media pembelajaran manual dan digital. Bogor: Ghalia Indonesia, 173.

Laurillard, D. 2007. edagogical forms for mobile learning in: Pachler, N. (ed) (2007) Mobile learning:towards a research agenda. London: WLE Centre, loE.

McEwan, T. \& Cairncross, S. 2004. "Evaluation and multimedia learning objects: towards a humancentred approach”. Jurnal Interactive Technology \& Smart Education. 2. PP $|0|-|| \mid$

Mulyasa, E. 2007. Standar Kompetensi dan Sertifikasi Guru. Bandung: Remaja Rosdakarya.

Nomor, P. P. R. I. (32). tahun 2013 tentang perubahan atas Peraturan Pemerintah Nomor 19 tahun 2005 tentang Standar Nasional Pendidikan. Dokumen Negara.

Peraturan Menteri Pendidikan Nasional Nomor 16 Tahun 2007 Tentang Standar Kualifikasi Akademik dan kompetensi Guru. Jakarta: Kementerian Pendidikan dan Kebudayaan Republik Indonesia.

Permadi, Ade S \& Rahmani. 2020. Analisis Penerapan Media Pembelajaran Google Apps For Education. Suluh: Jurnal Bimbingan Dan Konseling, 5(2):48-52.

Putra, Chandra Anugrah. 2017. Pemanfaatan Teknologi Gadget Sebagai Media Pembelajaran. Bitnet : Jurnal Pendidikan Teknologi Informasi, 2(2): I - I0.

Rahmawati. 2015. Jurnal Pendidikan. Diakses melalui

http://journal.student.uny.ac.id/ojs/inde

x.php/fiptp/article/view/727. diakses pada 16 novermber 2019

Rusyan, H.A. T. 20/4. Membangun Pendidik Berkualitas. Jakarta: PT. Pustaka Dinamika.

Rogozin. 2012. Physics Learning Instruments of XXI Century. Proceedings of The 


\section{TUNAS}

Jurnal Pendidikan Guru Sekolah Dasar

World Conference on Physics

Education 2012.

Rosida. 2017. Pengembangan Bahan Ajar EBook Interaktif Untuk Menumbuhkan Keterampilan Berpikir Kritis Siswa Pada Materi Dampak Pencemaran Bagi Kehidupan. Tesis Unila. Bandar Lampung: Universitas Lampung

Semi, A.M, 2008. Trampil Berdiskusi dan Berdebat. Bandung. Titian Ilmu.

Scott B. \& Cong, C. 2010. "Evaluating course designprinciples for multimedia learning materials". Jurnal CampusWide Information Systems 27 (5). PP 280-292

Suryo, M. dan Amin, M. 1982.

Pengajaran Remedial.jakarta:

DepdikbudP2BSPG. 